\title{
Participación comunal: retos, problemas y posibilidades
}

\author{
Jesús E. Machado M. \\ Centro Gumilla, Caracas, Venezuela \\ jesusmachado520@gmail.com
}

\section{Resumen}

La revolución bolivariana desde sus inicios puso como eje articulador la democracia participativa. Estimuló diversas formas organizativas para tal fin. En el marco de la declaración del carácter socialista de la revolución se crean los consejos comunales. Estas instancias convocaron, principalmente, a los sectores populares que atendieron el llamado -del para entonces presidente Hugo Chávez- de organizarse en estas instancias. Progresivamente se fue profundizando la propuesta de lo comunal dando paso a tema de la conformación de las comunas como unidades de agregación hasta constituir al Estado comunal.

La participación popular a través de los consejos comunales y comunas trae a colación nuevamente viejos debates como lo son el tema de la sujetualidad, la relación pueblo potencia-constituyente y Estado nacional, la autonomía del pueblo y sus organizaciones y la relación política con el partido que conduce al Estado. Lo comunal se convierte en una trinchera estratégica para la construcción democrática, participativa y protagónica de una sociedad postcapitalista, el comunismo.

Palabras clave: Participación comunal, Consejos comunales, comunas, poder popular, Estado comunal, comunismo

\section{Communal participation: challenges, problems and possibilities}

\begin{abstract}
From the beginning, Bolivarian revolution, has participatory democracy as its main pivot. For this purpose, it stimulated various organizational forms. In the context of the declaration of the socialist character of the revolution, the communal councils are created. These instances summoned, mainly, the popular sectors answering the, then president Hugo Chávez's call to organize in these instances. Progressively the proposal of the communal was deepened giving way to the conformation of the communes as units of aggregation until constituting the communal State.

The popular participation through the communal councils and communes brings up again old debates such as the subjectivity, the relationship power-constituent people and national State, the autonomy of the town and its organizations and the political relationship with the party leading to the State. The communal part becomes a strategic trench for the democratic, participatory and protagonic construction of a post-capitalist society: communism.
\end{abstract}

Keywords: Communal participation, Communal councils, communes, popular power, communal state, communism 


\section{Introducción}

Desde la entrada en la escena política del movimiento bolivariano ha tenido el tema de la participación y el protagonismo del pueblo como uno de sus ejes articuladores. De hecho el mismo proceso constituyente, el preámbulo de la constitución nacional vigente, la definición de gobierno y en una amplia cantidad de artículos del mismo texto se menciona de manera directa el tema de la participación y la democracia participativa. En la constitución actual se pueden rastrear unos 70 artículos referidos a la participación.

Los diferentes ensayos de diversas formas organizativas antes de 2006, son intentos por un escalamiento de la democracia participativa. La promoción de formas de participación popular y cierto nivel de autogobierno local (mesas técnicas de agua; comités de tierras urbanas; Comités de salud; mesas técnicas de energías, entre otras) han mostrado como desde la hegemonía en el control del Estado ha impulsado una política en ese sentido. En ello se inscriben los consejos comunales y muy seguidos las comunas y el Estado comunal.

Nos planteamos en este escrito un examen rápido sobre algunos temas vinculados a los consejos comunales (CC) y Comunas, además de las posibilidades, limitaciones, tensiones y obstáculos de los mismos para edificar una arquitectura postcapitalista.

\section{Un recuento sobre el origen de los CC y Comunas}

Para hablar de las potencialidades o no de los CC o Comunas en cuanto a la posibilidad de construir una sociedad postcapitalista bajo la forma de estado comunal, es pertinente hacer un muy breve recuento de su surgimiento, pues ello nos dará pistas para ver sus alcances y limitaciones.

Uno de los mayores esfuerzos que ha realizado el Gobierno Nacional en torno a la organización para la participación social ha sido a través de los CC.
El origen de estos bien la podemos rastrear hasta el texto constitucional de 1.999. El artículo 62 refiere a la participación popular en la gestión pública. El artículo 70 determina las formas de participación en lo económico, social y político. El artículo 182 establece la creación del Consejo Local de Planificación Pública (CLPP), el cual estaría:

"presidido por el Alcalde o Alcaldesa e integrado por los concejales y concejalas, los presidentes o presidentas de las juntas parroquiales y representantes de organizaciones vecinales y otras de la sociedad organizada, de conformidad con las disposiciones que establezca la ley".

En la Ley de los Consejos Locales de Planificación Pública, del 12 de junio de 2002, es donde aparecen por primera vez la mención de los CC:

"los miembros del Consejo Local de Planificación Pública estarán obligados a cumplir con sus funciones, en beneficio de los intereses colectivos, mantendrá una vinculación permanente con las redes de los consejos parroquiales y comunales, atendiendo sus opiniones y sugerencias, y prestará información oportunamente, de las actividades del Consejo Local de Planificación Pública." (Ley De Los Consejos Locales De Planificación Pública. Art. 6).

Los consejos locales de planificación pública no fueron aceptados tan fácilmente por las autoridades municipales quienes debían estimular su conformación. En vista de ello se modifica la Ley del Fondo Intergubernamental para la Descentralización (FIDES - Gaceta Oficial de la República Bolivariana de Venezuela $\mathrm{N}^{\circ} 5.805$ Extraordinario, de fecha 22 de Marzo de 2006) permitiendo la creación acelerada de estos consejos locales de planificación, ya que en su artículo 20 se exige que los programas y proyectos de las alcaldías deben ser presentados por los mismos CLPP para su aprobación:

“Los programas y proyectos serán presentados para su aprobación, en el caso de las gobernaciones a través de los Consejos Estadales de Planificación y Coordinación de 
Políticas Públicas; en caso de las alcaldías, a través de los Consejos Locales de Planificación Pública. Los programas y proyectos de los Consejos Comunales de acuerdo con lo previsto en su respectiva ley" (Ley que crea el Fondo Intergubernamental para la Descentralización)

Para junio del año 2005 se promulga Ley Orgánica del Poder Público Municipal. En este texto quedaba claro que los CC eran una instancia de los CLPP.

"Los consejos parroquiales y comunales son instancias del Consejo Local de Planificación Pública que tendrán comofunción servir de centro principal para la participación y protagonismo del pueblo en la formulación, ejecución, control y evaluación de las políticas públicas, así como para viabilizar las ideas y propuestas que la comunidad organizada presente ante el Consejo Local de Planificación Pública" (Ley Orgánica del Poder Público Municipal. Art. 112).

En el artículo 113, de esta misma ley, señalaba que: "el alcalde o alcaldesa en su carácter de presidente o presidenta del Consejo Local de Planificación Pública, promoverá la conformación de los consejos parroquiales y comunales..." A la luz de los hechos, poco fueron los consejos parroquiales y comunales promovidos por las autoridades municipales.

Desde mediados del año 2005el presidente Hugo Chávez realizó exhortaciones para la organización de los CC como forma de participación social. Los programas de "Aló Presidente"2 fueron una plataforma de amplia difusión para promover esta forma organizativa, a fin de estimular la participación organizada de las comunidades en la solución de los problemas más urgentes y cotidianos en relación al espacio social que habitan.

$\mathrm{Al}$ momento de rendir memoria y cuenta de lo actuado ante la Asamblea Nacional en febrero de 2006, el presidente de la República hace un llamado para que las comunidades se organizaran en CC, a la vez que exhortó a la Asamblea Nacional para que promulgara una ley sobre esta figura de organización comunitaria. El 7 de abril de 2006, se promulga la Ley de los Consejos Comunales y publicada en Gaceta Oficial Extraordinaria No. 5806 de fecha 10 de abril 2006.

La disposición transitoria de la Ley de los Consejos Comunales señala: “Queda derogado el artículo 8 de la Ley de los Consejos Locales de Planificación Pública y todas las disposiciones que contradigan lo previsto en esta Ley" con lo que se separan de los Consejos Locales de Planificación Pública.

Se reforma de la Ley Orgánica del Poder Público Municipal para suprimir la relación de los CC con las alcaldías y las juntas parroquiales.

En el artículo 30 se crea la Comisión Nacional Presidencial del Poder Popular, designada por el Presidente de la República, a través de esta comisión se establece el enlace de los CC con el Estado. Se trata de la conformación de instancias de participación comunitaria, sin cuerpos intermedios de relación con el ejecutivo. Estableciéndose una relación directa entre los consejos comunales y el Ejecutivo nacional.

En esta ley los CC son definidos como:

“... instancias de participación, articulación
e integración entre las diversas organizaciones
comunitarias, grupos sociales y los ciudadanos
y ciudadanas, que permiten al pueblo
organizado ejercer directamente la gestión de
las políticas públicas y proyectos orientados
a responder a las necesidades y aspiraciones
de las comunidades en la construcción de una
sociedad de equidad y justicia social." (Ley de
los Consejos Comunales. Art. 2).

A finales de 2009 se modifica la LCC y pasa a ser una ley orgánica. Con modificaciones de procedimientos y de relaciones con diferentes instancias del gobierno. Pero es necesario

1 Ídem. Art. 113.

$2 \mathrm{Al}$ respecto puede consultarse la siguiente dirección electrónica: [en línea]<http://alopresidente.gob.ve/ transcripciones/> 
destacar que se establece “...la construcción del nuevo modelo de sociedad socialista" (Art. 2)

Habría que decir también, como ubicación de contexto, que la creación de los CC se inserta en el momento histórico en el que, en voz del líder de la revolución bolivariana Hugo Chávez, esta se declara socialista. A la luz de lo acontecido, el modelo hacia el socialismo planteado estaría fundado en un modelo consejista de la revolución.

\section{Desarrollo de los Consejos Comunales}

Antes de la promulgación de la Ley de los Consejos Comunales, había organizaciones de este tipo partiendo de lo establecido en la Ley de Consejos Locales de planificación Pública.

A partir del mes de abril de 2006, hay un gran esfuerzo desde el Gobierno Nacional para la conformación de CC en el país. Según información del censo realizado por el Ministerio del poder popular para las comunas y movimientos sociales unos 45 mil dos CC están registrados al mes de agosto de 2015.

La creación de las comunas sigue un camino parecido. Veamos: En la propuesta de reforma constitucional de 2007 como intento de acelerar el proceso político, se plantea la reforma del artículo 16. Es allí cuando se introduce lo de la comuna y las ciudades comunales. La propuesta dereforma no fue aprobada y por tanto el intento de otorgarle rango constitucional a lo comunal queda postergado.

En diciembre de 2010 se aprueba La Ley Orgánica de las Comunas. Allí se establecen, desde la institucionalidad del Estado, los parámetros a seguir en la construcción de las mismas. Definiéndolas como células del Estado comunal, espacio socialista, soporte para la construcción de la sociedad socialista. Otros elementos a destacar es los diferentes sistemas de agregación comunal: CC, comunas, ciudades comunales, federaciones comunales, confederaciones comunales, serán establecidos por el reglamento de la ley.
Según censo del Ministerio del poder popular para las comunas y movimientos sociales unas 1212 comunas al mes de agosto de 2015.

No conocemos una data organizada que nos de cuenta de cuantas personas están involucrada de manera directa en la organización y funcionamiento de los CC, lo que hace difícil conocer la cobertura poblacional exacta de los mismos. Aun así, las estimaciones posibles que podamos hacer, estarían señalando que gran cantidad de personas están involucradas en las mismas.

Conociendo un poco el surgimiento de los CC y las comunas encontramos el primer punto de tensión.

Las formas organizativas comunales (para englobar CCyComunas) no parten deuna situación insurreccional en donde los sectores populares con sus organizaciones revolucionarias decidieron crearlas. Podríamos decir que tampoco su creación fue parte de un proceso de acumulación de fuerzas de las organizaciones sociales, revolucionarias y populares, con una experiencia amplia -en tanto contenidos y prácticas- de una democracia participativa y protagónica planteándose el objetivo histórico de construir colectivamente -desde abajo- el comunismo.

Son creadas desde arriba, desde el poder ejecutivo como un dinamizador de la participación social, otorgándoles una forma organizativa dentro de un cauce institucional del Estado -burgués ${ }^{3}$ para más señas. Detrás no existe un partido u organización revolucionaria que guía la construcción de lo comunal, ni existe un autogobierno total de estas formas organizativas populares y revolucionarias. Ellas están sujetas en gran medida a procedimientos legales y a los designios de una casta burocrática autoreferenciada de las diferentes instancias del gobierno del Estado. Su origen, tanto concepción, impulso, estímulo y sostenimiento institucional

3 En tanto sigue operando desde la misma lógica metabólica del capital. 
(legal-financiero-técnico) se encuentra en una iniciativa estatal.

Ello manifiesta una tensión-contradicción en el hecho de que el poder constituyente (pueblo) queda sometido al poder constituido (del que deriva), pues este último le señala al primero el modelo que debe seguir.

El poder constituido, que derivó de una voluntad mayoritaria mediante elecciones, direcciona el curso de la acción del constituyente originario, de tal modo que se hace ver que sus decisiones son las del constituyente originario, no siendo así. Pues esta representación llega al poder con un programa política que somete a la aprobación mayoritaria, pero no es una decisión mayoritaria en cuanto concepción y directriz.

¿El pueblo constituyente quiere socialismo porque así lo desea o porque la nueva hegemonía ha vendido la idea que así sea logrando su aprobación? ¿Cómo rescatar la voluntad de superar el capitalismo en caso de que la hegemonía gobernante quiera realizar un proceso de regresión?

No son respuestas fáciles, el proceso continúa su marcha en un devenir que no concluye. La historia no ha llegado a su fin.

\section{El tema del sujeto}

Parael desarrollodeestetemahay queabordarlo desde dos perspectivas una con respecto a lo concerniente a lo que subjetivamente llamamos sujetos y la segunda, a lo que se ha llamado sujetos sociopolítico de la acción histórica.

\section{La densidad de los sujetos}

En cuanto a lo primero es necesario sentarse a considerar sobre si existen condiciones en el medio popular para acometer la empresa de construir colectivamente un nuevo modo civilizatorio postcapitalista.

En principio habría que tomar en cuenta es si las condiciones materiales de existencia dentro de la formación social venezolana, caracterizada como un capitalismo rentístico-distributivo de Estado, salvaguarda y potencia todos los campos primordiales de la vida humana. Es decir, si la persona concreta del medio popular, es capaz de cualificarse para la producción -material e intelectual- con capacidad para construir un hábitat donde desplegar la vida, desarrollar relaciones mínimas de convivencia, en proceso de formación y cualificación, haciéndose cargo de manera crítica de la realidad (local, nacional hasta el nivel internacional), participando activamente en alguna forma organizativa socio-política que aporte significativamente al bienestar personal y colectivo (familiar y social), no se deja llevar con facilidad por los dinamismos degeneradores del medio social en el que se desenvuelve cotidianamente -a veces aplastantes- y toma postura consciente y solidaria frente a los hechos políticos, económicos, sociales y geopolíticos del país. Dueño de sí, con conciencia de su ubicación y posición social y de los dinamismos de opresión y dominación en la sociedad venezolana.

Si encontramos personas en el medio popular capaces de eso entonces la propuesta de la comuna, como expresión de la realización histórica del comunismo en Venezuela, es una propuesta viable.

De no ser así, la propuesta del comunismo, no será un horizonte deseable sino una fuente de alienación y como tal, despersonaliza. Ello en razón de que se gira en torno a ideas que se desligan de las condiciones concretas en la se vive cotidianamente. Por tanto, no habiendo sujetos reales individuales, en tanto personas, no habrá sujetos sociopolíticos autónomos de acción histórica.

No podemos afirmar que no existan estas personas en el medio popular, de ninguna manera. Las hay y mucho - y en proceso de formación hacia ello, pero no es posible afirmar que sean la mayoría. Es una porción significativa, pero que aún no logra generar un dinamismo diferente a lo que hoy presenciamos.

\section{El Sujeto sociopolítico de la acción histórica}

Desde finales de los 80 y a lo largo de la década de los 90 ha sido un debate central el tema 
del sujeto en las necesarias transformaciones históricas de las formaciones sociales capitalistas.

Hay nos encontramos en el mismo debate. ¿Es la clase obrera el sujeto histórico o por el contrario existe una multiplicidad de sujetos históricos?

K. Marx escribió sobre la agitación de las fuerzas y pasiones en la sociedad, de la subjetividad revolucionaria. Ello daba cuenta en un primer momento del proletariado, pero que en trabajos posteriores empezaría a dar cuenta de otras fuerzas y pasiones al examinar los procesos sociopolíticos de otras regiones en situaciones que no en el marco del desarrollo del capitalismo industrial de la Europa del siglo XIX.

Las fuerzas y pasiones en América Latina son protagonizadas por una multiplicidad de sujetos sociopolíticos. El dinamismo de la realidad histórica ha mostrado como han insurgido indígenas, mujeres, campesinos, trabajadores, pobladores, entre muchos otros. Superando de hecho la lectura reduccionista del marxismo expresado en una concepción limitada a lo económico, en el que se ponía al proletariado como único Sujeto de la acción revolucionaria. Ello aderezado con la concepción del partido-vanguardia, que representaba y encarnaba la subjetividad revolucionaria.

El afán de clarificar la subjetividad revolucionaria hoy, para el caso venezolano, no radica en determinar cuál es la fuerza que pone en marcha la maquinaria de la revolución sino en tener claro cuáles son las personas y grupos sociales concretos que están siendo sometidos a formas múltiples de dominación y con capacidad de iniciar procesos emancipatorios.

En nuestro caso, al tratar los CC y/o comunas, nos plantea como parte del sujeto histórico está actuando allí, en menor o mayor medida. La revolución venezolana tiene en esas formas organizativas comunales a una parte de la sujetualidad revolucionaria en acto, en efectuación concreta, teniendo como horizonte la construcción de una alternativa al capitalismo. Ya su sola existencia, con todas las dificultades que enfrenta, marca una posibilidad de que así sea.

Partimos del reconocimiento que las luchas emancipatorias no solo están referidas al totalitarismo del sistema-mundo capitalista, sino que también incluye un sistema múltiple de dominación y además las luchas reivindicativas y demandas de los sectores populares.

En todo caso hay que reconocer que el proceso revolucionario venezolano ha puesto de manifiesto un tema medular en el proceso de transformación y tiene que ver con lo relativo al tema de cuál es el sujeto que hace la revolución y eso a partir de la experiencia organizativa y política de los comunal. No es poca cosa.

Una subjetividad revolucionaria que a veces se condensa en el C.C. o en la comuna, o no, sin homogeneizarse. A veces solo como sujetos en ciernes, en potencia. Reconociendo a la vez que no todas las fuerzas y pasiones de la emancipación que hoy bullen en mayor o menor grado en la sociedad venezolana se encuentran en los CC o comunas, pero esos son lugares de expresión y práctica real estratégico.

La dinámica sociopolítica está en marcha, nada está definido, el tema de debate está ahí planteado. La síntesis del mismo no pasa exclusivamente por el campo de la teoría sino por lo que la realidad de este proceso va dando de sí, y eso es la efectuación de la conciencia que actúa y se actualiza como colectivo en el proceso de emancipación.

También es importante señalar que la experiencia con lo comunal no está marcada por la clase, en tanto ubicación en el modo de producción, sino por su anclaje territorial. Es entonces la comunidad, ${ }^{4}$ el sujeto individual, el vecino. Pero teniendo en cuenta lo que hemos dicho no es el única sujetuatidad revolucionaria. Sería injusto sostener que el futuro por hacer de la revolución venezolana descansa en lo

4 Tal como se define en la LOCC. Art. 4.1. 
comunal. Tiene este un enclave estratégico, pero no es el único.

Lo comunal tiene que ver con la capacidad de gobernarse colectivamente desde el territorio que se ocupa, la toparquía. Ello no significa que de profundizarse fallas que pongan en cuestión lo que hemos acumulado como experiencia de lo comunal, la revolución no va más. La multiplicidad de caminos y posibilidades en los gestas de los pueblos en procesos de emancipación son cuasi infinitos.

\section{La participación, sus condicionantes y motivaciones}

La literatura sobre la participación es abundante. Cada vez más el tema de la participación y cómo hacer los procesos más participativos va ganando espacios en todos los niveles y de distinta forma. Desde las familias hasta el sistema de las Naciones Unidas, pasando por agencias de cooperación privadas recomiendan y ven como el mejor modo para el desarrollo de dinámicas sociales y hasta planes de desarrollo hacerlo de modo participativo. Todas dan una definición particular y distinta de la participación, teniendo como resultado un océano de definiciones conceptuales.

Dada la naturaleza de este escrito nos decantaremos por una definición de participación muy amplia que permita abarcar todas las formas en que ésta se podría expresar, teniendo en cuenta una multiplicidad de fenómenos y asumiendo la riqueza de lo real-social.

En este sentido nos parece adecuada para nuestro estudio, la definición conceptual que hace Moreno (2003) sobre participación. Nos señala este autor que la participación es:

Un proceso complejo de actividad social construido sobre el ejercicio concreto, cotidiano y consciente de la misma, en el curso del cual las personas se integran a un todo grupal humano $[\ldots]$ como partes esenciales del mismo, de manera radicalmente inclusiva, en cuanto sujetos voluntaria y libremente activos, todos en igualdad de condiciones, oportunidades y posibilidades, compartiendo con los demás miembros del todo grupal las responsabilidades y la toma de decisiones en los proyectos, empresas y actividades que los afectan desde su concepción y elaboración hasta su ejecución, control y evaluación, aunque en ello estén implicados también cualquier tipo de instituciones externas, incluyendo los distintos niveles del estado, encaminando dicho proceso al logro del bienestar comunitario, a la solución de los problemas comunes, al desarrollo humano compartido y a la determinación autónoma del futuro personal y grupal de los agentes.

La participación en cualquier forma organizativa y fines de que se trate se efectúa en un contexto concreto, en donde intervienen un conjunto de variables estructurales, coyunturales, comunitarias, familiares, personales. No se produce en el campo de la ideación heroica de un pueblo que toma el cielo por asalto y se instala en el edén de las relaciones sociales emancipadas. La participación popular en lo comunal no escapa de ello, y más aún por ser popular. Veamos algunas de estas variables.

El investigador peruano Tanaka, M. (2001), al hablar de la participación, señala lo siguiente:

Planteo que no es posible pensar la participación en abstracto, al margen de las condiciones, los contextos en la que se produce. No considerar las diferencias que ellos determinan lleva a pensar en modelos inaplicables, o peor aún, contraproducentes. De otro lado, se suele pasar por alto el dato de que la participación es una construcción social, que implica costos y la superación de problemas de acción colectiva, con lo que está lejos de ser una práctica natural o espontánea. Por el contrario, depende de la existencia de recursos materiales o simbólicos movilizables, de la existencia y naturaleza de los liderazgos sociales, de la intervención de agentes externos, y de la estructura de oportunidades políticas establecida por el Estado. (p. 6)

La participación es un sistema constituido por diversos componentes que se influyen de modo recíproco obteniendo como resultado que los elementos intervinientes y el modo como intervienen, tienenuna repercusiónen los resultados. Además es de tener en cuenta que la participación 
es susceptible de experimentar límites en los espacios y tiempos de materialización.

\section{Los costos de la participación}

La situación de pobreza de una parte considerable de la población venezolana obliga a emplear la mayor cantidad de tiempo en las estrategias de supervivencia para hacer frente a la situación precaria en que se vive o resolver las frecuentes crisis económicas. Lo urgente siempre tiene la prioridad. La misma situación de precariedades y limitaciones dificulta establecer planes para el mediano plazo y más difícil aun para el largo plazo. Por ello, el empleo de recursos dinerarios y tiempo se plantea como una exigencia que va más allá de las propias capacidades que se posee. Las preocupaciones centrales están en la sobrevivencia y el agenciamiento de los asuntos muy particulares de la cotidianidad intrafamiliar, quedando poco tiempo, esfuerzo e interés para un compromiso de participación con la res-pública.

A lo que también habría que dejar constancia que, diciéndolo en clave marxista, la reproducción de las condiciones materiales de existencia en la Venezuela de hoy está bajo el modo de producción capitalista, es trabajo asalario. Mientras no se crean las condiciones para el trabajo libre y libremente asociado persistirá, como piedra de molino al cuello, la obligación de mantenerse en un puesto de trabajo para tener condiciones de reproducir la vida.

Con base en lo anterior, podemos afirmar que no es igual la participación de los sectores subordinados a la que desarrollan los grupos sociales de clase media o la ejercida por los sectores de clase alta, dada los condicionantes socioeconómicos que la caracterizan. Lo que también permite decirqueel grado de desigualdad existente en la sociedad es un limitante de la participación.

Participar en un consejo comunal o en la comuna demanda dedicar largas horas en reuniones de intercambios, coordinación, planeación, formación, de ejecuciones de lo planeado. Teniendo en cuenta lo inmediatamente dicho en los párrafos anteriores es de preguntarse sobre las disponibilidades que realmente se tiene para ello. Lo comunal avanza no al ritmo de las intencionalidades de las élites de los partidos o gobernantes. Lo hace al ritmo que marca el desarrollo de la vida en el medio popular.

Una concepción muy particular del leninismo, entendía el cuadro revolucionario como aquel sujeto que prescindía de todo para consagrarse a la causa revolucionaria. Un profesional de la revolución.

En el medio popular, quienes participan no son cuadros revolucionarios liberados, no son unos profesionales de la participación -ello no niega que existan personas que así vivan. Se participa a partir del tiempo que se libra de las obligaciones de lo que se considera fundamental para el sostenimiento de la vida personal $y$ familiar.

\section{Ni natural ni espontánea}

Como segundo elemento tenemos la constatación de que la participación no es una práctica natural y espontánea, esta debe ser estimulada también con formación democrática como método y contenido, así como también la autoeducación continuada para el ejercicio de la participación. Sin estos elementos no se pueden desarrollar habilidades que permitan participar en los asuntos colectivos.

Las facilidades que se puedan brindar desde actores externos como el Estado o redes privadas para dar causes a la participación se constituyen en elementos que pueden facilitar una acción deseable como la participación protagónica. De allí que el problema, desde mi perspectiva no es tanto que el Estado estimule formas diversas de participación y las financie. Las condiciones concretas de la población que participa, y que se desea que participe, exige de suyo auxilio externo para ello. El problema está en la utilización-manipulación de una hegemonía con fines meramente instrumentales a la élite gobernante. 
Dado el desarrollo de los CC y su dependencia de presupuestos públicos canalizados a través del Ejecutivo nacional, gobernaciones y alcaldías, están tremendamente expuestos a chantajes y manipulaciones de quienes manejan los recursos económicos.

En declaraciones del gobernador del estado Guárico (2008), Willian Lara, señalaba que:

\begin{abstract}
"los consejos comunales, cuya trayectoria, como manifestación auténtica del Poder Popular, se ha topado en algunos sitios con grupos de poder político y económico que le han impuesto alcabalas, peajes, sometiéndolos a presiones lesivas a su autonomía, independencia y soberanía, por ejemplo con la práctica $[. .$.$] de$ exigirles incondicionalidad política como precio del derecho a recibir financiamiento de sus proyectos. La más brutal expresión del secuestro delos consejos comunales, del sometimiento de su soberanía por el chantaje de los burócratas que administran el presupuesto público..."
\end{abstract}

La ministra del Poder Popular para la Participación y Protección Social (año2009), Erika Farías, dadas en un acto en el Teatro Teresa Carreño señalaba que:

"A partir de este momento, cada consejo comunal se constituye en un comité por el Sí. Es un órgano del poder. Todos deben ser organizaciones para la Batalla del Sí. Comités de tierra, mesas de energía, mesas de telecomunicaciones son comités por el Sí (...) Hay que entender que es un trabajo político; hay que dejar de lado cualquier otro proyecto para poner la lucha. Ninguno de los problemas que vamos a solucionar en la comunidad podemos abordarlo sin una fuerza". ("Gobierno obliga a consejos comunales a trabajar por el Sí”, 2009).

El luchador social Santiago Arconada (2009), señalaba que muchos consejos comunales los están convirtiendo en apéndices del Partido Socialista Unido de Venezuela (PSUV) y que esto constituye la mejor formar de aniquilar esta experiencia organizativa.

La autonomía de estas formas organizativas populares debe ser estimulada para que puedan dar de sí lo que en ciernes está, y no sea arrastrado por las decisiones y contingencias de élites gobernantes.

\section{Las motivaciones}

Un tercer elemento importante son las motivaciones que se tienen para realizar algún tipo de participación. En medio de situaciones de necesidad y sobrevivencia cotidiana donde las redes primarias de relaciones sociales (familiares, amigos, paisanaje, etc.) se constituyen en el soporte para garantizar esta sobrevivencia la asociación con otras personas para la búsqueda de soluciones comunes a problema comunes está dificultado por que cada núcleo relacional social primario está centrado en lo más básico. Solo en caso en que la situación ambiental es de tal magnitud que se impone y obliga a formas espontáneas de asociación y algún tipo de acción para hacerle frente. Este tipo de formas de participación tiene poco durabilidad en el tiempo. Son tipos de asociaciones y participaciones que se articulan en base a problemas tan específicos que una vez paliados o resueltos estas formas de participación se diluyen.

El cuarto elemento que consideramos está relacionado con lo simbólico, desde una experiencia reciente de rechazo a todo lo que tenía que ver con lo político, la existencia de ese desencanto que impedía la convocatoria a formas asociaciones o redes para la atención de problemas que incumben a las mayorías de las personas. Cuando cambian esas concepciones y se plantea la posibilidad de creer nuevamente en la política se constituyen en nuevo estímulo para la participación y se recupera a lo social de la postración, de la apatía por lo que es común a todo. Que se convierte en un círculo vicioso, hay problemas reales que afectan a todos que sin motivación alguna no se resuelven agravando las situación de depresión social que impide la organización para superarlo situación que se repite una y otra vez hasta que se puede romper el círculo vicioso.

La desigualdad social tanto como la de capacitación implica de modo directo la extensión y calidad de la participación. En sociedades con desigualdad socio-económica y 
formativa la participación es desigual porque desiguales son las condiciones de los sujetos que en ella toman parte.

El Estado debe estimular la participación entendiendo que a mayor participación social se crean beneficios mayores para todos.

La necesaria escucha de demandas y propuestas, para el diseño y ejecución de políticas públicas permitían una mayor efectividad en la resolución de los problemas de las personas y fomento de una cultura democrática en las personas que cada vez más se hacen cargo de lo público y lo hacen porque pueden obtener resultados tangibles que con estas forma de actuación la vida mejora no solo para sí sino también, y por eso, la del colectivo.

Muchos de los vicios gubernamentales pueden ser superados cuando la participación de las personas permite una visión sobre sus problemas, además de un control y una supervisión de los funcionarios de los gobiernos.

La participación también adopta diferentes niveles en los que las personas participan, como por ejemplo el nivel de colaboración y asistencia el cual es muy puntual y acotado a actividades periféricas; o en niveles más comprometidos como lo son aquellos en que las personas asumen un rol activo en la difusión y promoción de sus objetivos así como en la planificación y ejecución de acciones. Por lo general, dentro de un mismo proceso participativo, las personas se ubican en uno y otro nivel, mostrando a veces diferencias cuantitativas entre uno y otro ya que, dependiendo del compromiso. De cualquier modo, ambos niveles resultan fundamentales para un proceso participativo y es necesario que ambos coexistan.

Adicionalmenteaello, encontramosqueexisten diferentes tipos de participación dependiendo del alcance y propósitos que se persigan. En el contexto de este trabajo resulta pertinente identificar la participación comunitaria, la participación política, la participación ciudadana y la participación social. Todas ellas comparten un elemento común referido a la participación en asuntos públicos que resultan de interés para un determinado colectivo. En ese sentido, el tipo de asunto en que se participa puede incluir, por ejemplo, aspectos relacionados con la mejora del equipamiento y los servicios de una comunidad, la discusión colectiva de una ley, la elección de gobernantes y hasta las grandes movilizaciones para apoyar, demandar o tomar parte de decisiones trascendentales para un país.

\section{Componentes de la participación}

Sumado a todo esto, encontramos también un conjunto de factores que constituyen una estructura así como condiciones y subprocesos que canalizan todo proceso de participación, independientemente del tipo que éste sea. Se trata de componentes que, según sea su adecuación al tipo de participación, se convierten en condiciones que la favorecen o la obstaculizan. Estos componentes son: los fines o propósitos de la participación; la motivación y razones de las personas para participar; la forma en que se organizan para participar; el tipo de liderazgo que se desarrolla en el proceso participativo. Veamos con mayor detalle cada uno de ellos:

\section{Los fines de la participación}

Todo proceso participativo tiene, necesariamente, un fin o propósito determinado que persigue, el cual es uno de los principales factores para promover y mantener la participación en el tiempo. Este fin, asimismo, se deriva de la necesidad que sienten quienes participan de cubrir una carencia, resolver una determinada necesidad o satisfacer una expectativa, que pueden ser desde las más puntuales y sencillas hasta las más integrales y complejas. Así, un proceso participativo puede promoverse para reparar una calle en una comunidad que afecta a los vecinos, para discutir un proyecto educativo que afecta a alumnos, maestros y padres $\mathrm{y}$ representantes, así como para apoyar u oponerse a un determinado gobierno cuya gestión afecta a la población entera. El caso es que en la medida que el fin esté claro y sea compartido por quienes participan, el proceso de participación puede mantenerse en el tiempo con bastante fuerza. En caso contrario, podremos observar como 
ese proceso participativo fluctuará entre picos circunstanciales de entusiasmo y momentos de dispersión y apatía, pudiendo llegar incluso a extinguirse por completo.

\section{La motivación}

La participación es asunto de individuos y, como tal, mantiene un estrecho vínculo con las características propias de las personas y sus modos de relacionarse. $\mathrm{Y}$, en ese sentido, una de las características humanas que mayor peso tiene en relación con el proceso participativo es la motivación. En efecto, no podríamos concebir un proceso participativo sin el impulso y la fuerza que solo la motivación de quienes participan pueden imprimirle. Participar, en cualquier de sus niveles y tipos, siempre resulta una cuestión difícil y complicada ya que requiere que las personas dediquen un gran esfuerzo y buena parte de su tiempo a ello. En ese sentido, deben realizar un gran esfuerzo para llevar adelante las tareas y trabajos propios que exige el logro de los fines que se proponen así como también deben invertir tiempo y esfuerzo para informarse y capacitarse en diversas áreas.

Frente a todo ello, no son pocos los que se terminan por desanimar y abandonan los procesos participativos. De hecho, podríamos decir que este es uno de los factores centrales que permite explicar la causa del fracaso de muchas experiencias participativas que, aun cuando comenzaron con mucho entusiasmo, terminaron extinguiéndose en la medida que fue disminuyendo la motivación de quienes formaban parte del proceso de participación.

En ese sentido, es pertinente considerar dos aspectos fundamentales para mantener la motivación en los procesos participativos. El primero tiene que ver con la capacidad de concreción que tiene la participación para lograr los fines que se propone. Dicho de otro modo, la motivación se mantendrá en la medida que las personas que participan logren cubrir la carencia, resolver la necesidad o satisfacer la expectativa que los motivó a participar. En la medida que el proceso participativo muestre resultados positivos al respecto, la motivación se mantendrá e incluso es muy posible que aumente. Por el contrario, en la medida que los fines propuestos no se concreten, la motivación descenderá y, con ella, también lo hará la participación hasta llegar incluso a desaparecer.

Mucho de la participación que se desarrolla en los CC y en las comunas está relacionado con la cantidad de recursos institucionales transferido por el Estado con la finalidad reformar el espacio en el que las comunidades populares desarrollan su vida. En la medida en el que hay retrasos en la transferencia de recursos y se presentan dificultades en la concreción de los proyectos comunitarios la participación tiende a disminuir. Caso contrario, cuando la comunidad ve concreción de los proyectos realizados tiende a participar más de estas formas organizativas.

El segundo tiene que ver con otros resultados de la participación que no se relacionan directamente con los fines propuestos pero que igualmente tienen efectos sobre la motivación de las personas. Se trata de mejoras que las personas identifican en sí mismas como por ejemplo el enriquecimiento de sus conocimientos, las posibilidades de conocer otras personas y otros puntos de vista, el desarrollo de competencias y habilidades personales como desenvolverse en el ámbito público, así como la experiencia de un sentimiento de utilidad y trascendencia que puede llegar a ser muy valorado. Todo ello, tiene un impacto altamente positivo en la motivación de las personas para participar, al punto que puede llegar a ser un sostén motivacional del proceso participativo en momentos en que no se logran aun alcanzar los fines.

En esta dimensión de la participación seincluye toda la dimensión simbólica del reconocimiento de los sectores populares de parte de una figura de poder. En este caso, la relación establecida por los sectores populares con él para entonces presidente Hugo Chávez. En el este último "hizo existir" a los sectores subalternizados convirtiéndolos en ejes de parte de su política y acción discursiva, en correspondencia con ello se desarrolló una relación de lealtad que implicaba un seguimiento a propuestas que emanaran del ejecutivo. No es gratuito que miles de personas 
de populares se volcaran de manera masiva en la construcción de CC.

Pueden también presentarse efectos negativos de la participación igualmente independientes de los fines, que tienen que ver con un conjunto de condiciones y situaciones con las que las personas se tienen que enfrentar en el proceso participativo. Así, por ejemplo, las personas se enfrentan a muchos conflictos, demandas y exigencias por parte de la gente, de las instituciones y hasta de la propia familia que muchas veces resiente el tiempo que invierte la persona en participar. Igualmente, es bastante común que quienes participan en el ámbito público, paguen las consecuencias de su exposición al ser blanco permanente de críticas e incluso de acusaciones de faltas y omisiones.

Ello se puede ver claramente en todo aquellos casos en el que las personas más vinculadas a la planeación y obtención de recursos para los proyectos comunitarios se enfrentan a una burocracia poco eficiente para destinar los recursos a las comunidades, produciendo que estas últimas hagan demandas y reclamos injustos a determinadas personas. Siendo estas sometidas a fuertes presiones.

Como podemos ver, la motivación al tiempo que representa una suerte de "combustible" fundamental del proceso participativo, es un factor que puede mostrar un signo positivo o negativo, convirtiéndose así en un factor que ayuda y promueve la participación o en un factor que la obstaculiza y la inhibe.

La existencia de motivación de modo relativamente homogéneo en los colectivos permitirá la viabilidad de los proyectos o las propuestas a que sean convocados, puesto que estos contarán con altos niveles de compromiso y elevadas cotas de legitimidad.

\section{La organización}

Para que la participación pueda mantener su dinamismo $\mathrm{y}$, al mismo tiempo, lograr sus fines requiere contar con una organización que permita canalizar las acciones en forma ordenada y congruente. Todos los procesos participativos, desde los más simples hasta los más complejos, se articulan en algún tipo de estructura dentro de la cual las personas se ubican en función de roles, funciones y procedimientos a través de todo lo cual "fluye" la participación. Esta organización que puede ser informal o puede llegar a convertirse en una figura altamente formalizada incluso desde el punto de vista jurídico, representa un instrumento fundamental para el intercambio, la toma de decisiones y la planificación y ejecución de acciones conjuntas en función de un fin compartido, todo lo cual no es otra cosa que un proceso de participación organizado.

Hay dos grandes beneficios que supone la organización para la participación. El primero de ellos es garantizar el flujo de información así como la generación de los espacios de discusión, intercambio y toma de decisiones conjunta entre todas las personas que están participando. El segundo, es la eficiencia que puede lograrse en la medida que todas las actividades que supone un proceso participativo pueden ser orientadas dentro de un orden que debiera, por un lado, impedir la dispersión de esfuerzos y la duplicación de tareas. Por el otro, favorecer la maximización de los recursos.

Todo ello conduce a considerar la importancia fundamental que tiene la organización para la participación, aun cuando esto no debe ser sobreestimado. La estructura organizativa debe ser, como ya lo hemos anticipado, un instrumento para la participación $\mathrm{y}$, aun cuando es necesario promover su desarrollo debe cuidarse de no convertirse en un fin en sí mismo que termine por condicionar el proceso participativo a sus propias condiciones de funcionamiento. En ese sentido, son muchas las experiencias organizativas que hemos visto en el contexto político partidista y comunitario que comenzaron canalizando la participación de la gente para satisfacer sus necesidades y expectativas pero terminaron respondiendo al mandato de unos pocos que en nada tomaban en cuenta el concurso de los demás. Esto condujo, invariablemente, no solamente al fracaso de estas organizaciones (partidos políticos, asociaciones de vecinos, entre otras) sino también 
a la desmovilización del proceso participativo con el consecuente sentimiento de frustración y apatía.

Ese es un punto al cual nos enfrentamos hay día. Se hala de la participación de las comunidades populares y en no pocos casos se instrumentaliza para fines partidistas coyunturales que poco a poco van mimado a los ánimos de las personas y termina desmovilizándolas. Visto desde el proceso revolucionario, en lo que supone un grave peligro pues mucho de las batallas frentes a las pretensiones restauradoras de orden del capital se han logrado gracias a la movilización de los sectores populares. Y de ello no se escapan los sectores populares que están en las organizaciones comunales.

\section{El liderazgo}

En todo grupo u organización, sea cual fuere su escala, desde una familia hasta la sociedad completa, encontramos siempre y necesariamente presente, el liderazgo. Sabemos muy bien el peso que éste tiene en todo emprendimiento humano $\mathrm{y}$, especialmente, en aquellos que implican a un colectivo. En efecto, el liderazgo puede ejercer una notable influencia sobre aspectos tales como la comunicación entre las personas, la motivación, la identidad, la cohesión grupal y la conformación de equipos, la resolución de problemas y conflictos, entre otros. Por ello y en función de todo lo que ya hemos expuesto, su relevancia para el proceso de participación es más que evidente.

Ahora bien, esta influencia puede ser tanto positiva como también negativa $\mathrm{y}$, al respecto, la historia de la humanidad es abundante en ejemplos de liderazgos políticos que muestran sus efectos tanto en un sentido como en el otro. Llevado el asunto al plano de la participación comunal, ocurre exactamente lo mismo. Existen ciertos tipos o estilos de liderazgo que pueden, en un momento determinado, promover positivamente el proceso de participación, así como existen toros que pueden promover la pasividad y hasta la apatía.

Entre los primeros, encontramos líderes que promueven en forma permanente la participación activa delas personas, motivándolas a desarrollarse, a dar de sí y a capacitarse, así como a asumir un rol cada vez más protagónico dentro del proceso de participación. Son líderes que, sin dejar de asumir su papel orientador e incluso de dirección, promueven la delegación, la distribución de las tareas y la conformación de equipos en un marco de corresponsabilidad.

Entre los segundos, encontramos líderes que suelen acaparar la mayor cantidad de tareas y actividades y no suelen delegar casi ningún tipo de responsabilidad en los demás. Asimismo, su interacción con las personas no produce toma de decisiones conjunta sino que la mayoría de las veces se queda en el intercambio de opiniones pero reservándose la decisión para sí o influyendo de manera persuasiva sobre los demás. Muchas veces la relación entre este tipo de líder y el resto, está marcada por la admiración y el agradecimiento hacia su persona, lo cual lejos de promover la corresponsabilidad, afianza la sumisión y la pasividad.

Como puede suponerse, el proceso de participación encontrará un canal apropiado para su desarrollo en el primer estilo de liderazgo en tanto que encontrará en el segundo estilo, condiciones que lo obstaculizan.

Pero el problema es que el liderazgo está asociado con un marco cultural que genera condiciones para uno $\mathrm{u}$ otro estilo $\mathrm{y}$, por lo tanto, para que surja la participación o para que las personas se mantengan al margen de ella. En ese sentido es necesario destacar también que, uno y otro estilo de liderazgo pueden resultar eficientes dependiendo del contexto y de las circunstancias. Así, el estilo democrático de liderazgo que hemos descrito aquí, es el más apropiado cuando existen condiciones normales de convivencia y las personas tienen la posibilidad de desarrollarse y llevar adelante sus proyectos. Sin embargo, el segundo estilo es el más adecuado en condiciones de peligro, amenaza o emergencia. Lo cierto del caso es que en lo que a participación comunal se refiere, no parece caber duda sobre la necesaria adscripción al primer estilo. 
En relación con este aspecto del liderazgo y la participación nuestra realidad muestra un panorama caracterizado por las contradicciones y la ambivalencia ya que, por una parte, vivimos tiempos de alta efervescencia participativa de todos los tipos (comunitaria, social, política) dentro de la cual se inscribe buena parte de la población venezolana. $\mathrm{Al}$ respecto, parece bastante claro que existe un cierto deseo y voluntad extendido por participar. Sin embargo, parece continuar predominando un cierto estilo de liderazgo que se adscribe más al tipo vertical, autoritario y poco participativo que hemos descrito aquí.

Esto no es sorpresivo ya que en nuestra sociedad existe una larga tradición caudillista que atraviesa casi la historia republicana completa del país y que ha perneado en casi todos los estratos y casi todas las esferas. Pero además, es bueno también recordar que la gran mayoría de nuestra población (casi el $70 \%$ ) ha vivido en condiciones de pobreza (desde la pobreza moderada hasta la pobreza extrema) y exclusión, lo cual generó en estos sectores mayoritarios una suerte de "cultura de emergencia" dentro de la cual, necesariamente, se cultivan los liderazgos de este tipo autocrático ya que resultan los más adecuados en esos contextos.

Todo ello, en parte, explica porque razón las organizaciones y los grupos aun cuando se propongan llevar adelante procesos participativos, casi siempre muestran cierta tendencia a generar condiciones para este tipo de liderazgo que suele tener efectos tan negativos para los procesos participativos.

\section{El rol del Estado en el fomento de las organizaciones comunitarias}

Con la aprobación de un nuevo texto constitucional en 1999, se da un nuevo impulso a las formas participativas posibilitando la aparición de diversos tipos de las mismas. A lo que habría que añadir la estimulación profunda que hace el actual presidente de la república para la organización social comunitaria. En el texto constitucional existen, al menos, existen unos 70 artículos que promueven la participación ciudadana en varios aspectos de la vida pública del país. Algunos de ellos hacen alusión directa a la participación popular.

El mismo Estado nacional se ha reestructurado para facilitar la organización a través de mecanismos de información y atención ciudadana (líneas telefónicas gratuitas de atención, servicios de recepción y entrega documentos, servicio de taquilla única, horarios especiales de atención); estructura institucional gubernamental (Sistema de Planificación, Sistema Nacional de Control Fiscal, Sistema deParticipación y Planificación Social); reconocimiento de derechos (Derecho de petición, Derecho de información, Derecho de queja y reclamo, Derecho de ser consultado, Derecho de formular opinión, Derecho de presentar propuestas).

Promulgación de leyes en las que se alude de manera directa la participación social en los procesos que deben llevar a cabo instancias del gobierno, tales como la Ley Orgánica de Planificación; Ley de Asignaciones Económicas Especiales derivadas de Minas e Hidrocarburos (2006).

La actual administración gubernamental elaboró un documento titulado Líneas Generales del Plan de Desarrollo Económico y Social de la Nación 2001-2007, que marca las directrices para la creación de de formas organizativas desde el poder central. A partir de estas Líneas Generales, el Estado se concibe como un facilitador del proceso de organización y participación dirigidos a la creación de un poder popular.

En la Gaceta Oficial Extraordinaria N ${ }^{\circ} 5.890$ del 31 de julio de 2008, salen publicados un conjunto de veintiséis (26) decretos con rango, valor y fuerza de Ley que abordan diferentes materias. En 14 de las cuales hay mención a CC, otras formas de organización y participación comunitaria, participación popular, formas de organización social, cualquier forma de organización y participación comunitaria, las comunidades organizadas.

A partir de la promulgación del texto constitucional de 1999 y con mayor énfasis a partir del 2006, se ha estado estimulando 
fuertemente la participación y la organización social comunitaria disponiendo gran cantidad de recursos económicos, técnicos y logísticos para fortalecer lo que desde la nueva hegemonía en la conducción del Estado ha llamado la construcción del Socialismo del Siglo XXI, teniendo como uno de sus pilares el Poder Popular.

A finales de 2010 se promulgan un conjunto de leyes para fortalecer el Estado Comunal, entre ellas están: Ley Orgánica del Poder Popular; Ley Orgánica de las Comuna, Ley Orgánica del Sistema Económico Comunal, Ley Orgánica de la Contraloría Social, Ley Orgánica de la Planificación Pública y Popular.

Posteriormente se aprobaron otras leyes que vendrían a completar las ya mencionadas, entre ellas tenemos: Ley Orgánica del Consejo Federal de Gobierno y la Ley Orgánica para la Gestión Comunitaria de Competencias, Servicios y otras Atribuciones.

Los actos de promulgación de leyes, aun cuando se le adjetive con lo popular entraña un peligro. La élite en la conducción del Estado se entiende que promueve la organización comunal y el poder popular porque lo coloque en un instrumento jurídico. Y algo de manejo común es saber que todo acto legislativo tiene vigencia mientras exista una correlación de fuerzas que lo sustente.

Poner los esfuerzos en la elaboración y promulgación de instrumentos jurídicos y no centrados en los procesos reales de organización, politización y movilización de las comunidades populares muestra una visión bastante liberal por un lado y por otro lado timorata y de corto alcance. Un cambio en la correlación de fuerzas en la Asamblea Legislativa podría desmontar en pocos pasos el andamiaje legal de lo que se ha hecho de promoción de lo comunal y el poder popular. No así si participación comunal se encuentra altamente politizada, en movilización permanente con capacidad de disputar el poder en las calles frente a las pretensiones regresionistas de los operadores locales del orden del capital.

\section{La instrumentalización política}

\section{¿Poder popular para el autogobierno?}

Es necesario preguntarse cuáles son las actividades en las cuales se emplean los CC. Teniendo en cuanta la distancia de su realización (Machado, 2009) y el dinamismo de la realidad histórica, amén de la ausencia de datos más actualizados, traigo a colación algunos resultados de una investigación sobre los CC.

Básicamente los CC emplean gran parte de su tiempo en tratar de resolver problemas de infraestructura, en especial la infraestructura habitacional y servicios concomitantes. Ante la pregunta ¿Cuáles proyectos ha puesto en marcha este consejo comunal en esta comunidad? Las respuestas fueron las siguientes: “...Casi de manera absoluta señalaron proyectos de infraestructura pública, urbanismo y servicios. Para viviendas $23 \%$, si le sumamos lo del programa Sustitución de Vivienda (SUVI), un $10 \%$, llega a $33 \%$, una diferencia bien marcada con respecto al resto de los demás proyectos. Red de agua potable y servidas $21 \%$; vialidad $15 \%$; electrificación $14 \%$; obras relacionadas con el deporte 13\%; construcción sede de CC 12\%; obras para escuelas $12 \%$; aceras, caminerías, escaleras $10 \%$; plazas, parques $4 \%$.

Formular y ejecutar proyectos, a partir de transferencia de recursos estatales para mejoras locales. Ello ha supuesto, en la práctica un acotamiento, bien reducido, de la participación popular en CC. Pues la actuación participativa se agota en la confección, obtención de recursos, ejecución entrega de cuentas de proyectos. Que dicho sea de paso, en la comunidad termina introyectando conflictos que originariamente son pueblo-Estado, pasando a ser una situación conflictiva pueblo-gestor Vs. pueblo receptor.

Esas dinámicas desvían el centro real del conflicto, encubren la contradicción principal. No se ve al opositor de clase ni al Estado como los sujetos a quienes enfrentar en perspectiva de desmontar la estructura de clase-dominación y la construcción política que le es funcional. 
Por otra parte, el conflicto se efectúa a lo interno de los sectores populares y subalternizados. Estos conflictos secundarios horizontales minan la cohesión interna en tanto que el contradictor del conflicto es el vecino. Con la consecuencia directa de relentizar los procesos unitarios tanto ideo-políticos como organizativos en el seno de lo popular.

Ciertamente se presenta inserción precaria de quienes participanenCCen procesosestructurales, como lo sería superar alternativamente el capitalismo. No se tiene ni la primera ni última palabra en lo que a orientaciones estratégicas se refiera para la construcción de una alternativa postcapitalista, en muchos casos se participa en talleres de formación, información, como masa para aumentar el volumen en movilizaciones, pero no como un sujeto sociopolítico.

\section{Algunas notas de valoración política}

Uno de los principales problemas que nos enfrentamos al tratar a lo comunal como posibilidad de construcción de un arquitectura estatal no liberal sustentada en un modo de producción no capitalista, está referido a los elementos que ya hemos señalado anteriormente: Creación gubernamental desde arriba de las formas organizativas comunales.

El problema no estaría tanto que el gobierno los haya creado, estimulado y dotado de recursos, sino es el tema de su instrumentación política por parte de la nueva hegemonía en el control del Estado que institucionaliza y direcciona, según sus intereses particulares, a la potenciaconstituyente de lo popular, secuestrando su autonomía.

Ese modo de actuar conduce a la despolitización y la desmovilización del poder popular constituyente en tanto que se direcciona no a lo estratégico, la transición al comunismo, sino a lo inmediatista partidario. Y el partido no encarna, no es la vanguardia de la potencia popularconstituyente $y$ sus formas organizativas comunales.

\section{Lo comunal sí}

Ya hemos descritos un conjunto de elementos que harían pensar que los comunal es una pérdida de tiempo y ocasión para la profundización de la revolución en Venezuela. Por el contrario, mucho de lo que ha mostrado el pueblo al volcarse masivamente a participar, con todo lo que hemos dicho, en lo comunal da muestra que existe una potencia en cuanto sujetualidad revolucionaria actuante, como forma organizativa, como planteamiento de trascender alternativamente el sistema mundo del capital.

Lo que hemos vivido desde lo popular no puede ser despreciado, hay allí un acumulado histórico en cuanto experiencia de participación democrática -de forma parcial y limitadade autogobierno micro local. La democracia participativa y protagónica de la sujetualidad revolucionaria popular y la construcción del comunismo no es un proceso que se produce por sortilegio mágico de la noche a la mañana. No se amanece en el comunismo, este se efectúa a través de las prácticas relacionales, simbólicas, discursivas, productivas, de construcción de poder que toma el tiempo que toma.

El paso de articulación de los distintos CC en determinado espacio geográfico para la conformación de la comuna muestra un avance. Algunos años atrás la desconexión entre distintos CC de un mismo perímetro era más que evidente, se entendían como un archipiélago de CC, hoy podemos señalar que eso se ha modificado. Lo que muestra que la existencia de errores que pueden parecernos fatales hoy, con la acción apropiada en el momento correcto puede ayudar a ir conformando ese todo otro poder.

\section{Participar no es cosa fácil}

Participar en lo comunal como proceso y método de construcción de una sociedad poscapitalista implica una serie de condicionamientos tanto a nivel de los sujetos, individualmente considerados, así como de la acción colectiva en vinculación creativa con los operadores en el gobierno sin perder la autonomía en proceso mismo. 
La participación requiere de sujetos que sean capaces de estar en procesos de formación y cualificación permanentes. Asumiendo la construcción de su propio hábitat. Con un mínimo de relaciones armoniosas con los vecinos. Capaz de hacerse cargo de manera crítica de las dimensiones de la realidad. Participando activamente en alguna forma organizativa socio-política que aporte significativamente al bienestar personal y colectivo (familiar y social). Con creatividad para construir formas colectivas de lo referente al trabajo reproductivo. Desde su densidad personal enfrentar las situaciones degeneradoras del medio en el que está inserto. Posicionándose de modo consciente y solidaria frente a los hechos políticos, económicos, sociales y geopolíticos del país.

Con esos condicionamientos mínimos personales participar en la construcción del comunismo se convierte en un proceso fértil que da mucho de sí, en tanto los sujetos hacen suyo un horizonte distinto a lo existente partiendo de las propias fortalezas internas.

Pero de suyo no basta que existan personas con esas características. Ello tiene que articularse con el conjunto de condicionamientos exógenos (al sujeto popular) y estructurales.

Para ello es imprescindible que pueda articularse con el conjunto de subalternidades existentes y a partir del reconocimiento mutuo así como el establecimiento de las esferas donde se entrecruzan las prácticas opresivas del sistema de dominación múltiple y plantearse un horizonte poscapitalista desde lo que hasta ahora se ha conocido de participación en lo comunal en dinámicas de autonomía y radicalmente democráticas frente a las directrices de las hegemonías que administran el Estado nacional.

Loscondicionamientosexógenosy estructurales tienen que ver con las mismas condiciones materiales de existencia. Es necesario superar el trabajo asalariado, con las formas de trabajo libre, libremente asociado. Es una condición que demanda mucha creativa y empeño para liberar las múltiples sujetividades emancipatorias. Ello ayudaría a superar la dependencia del auxilio para participar que da el actual Estado nacional.

Por otra parte es necesario reconocer que las fuentes de la motivación para participar están relacionadas a las ventajas (de orden material inmediato) que se pueden obtener, pues esas motivaciones iniciales tienen que evolucionar hacia fines mayores. No se trata solo de los beneficios que se obtengan a través de un mecanismo institucional gubernamental sino de construir colectivamente otro modo de existencia.

Hay que saber ubicar en cual nivel y cuál es el propósito para la participación, de manera que no creen expectativas que no serán cumplidas y luego padecer los efectos negativos que ello acarrea. Establecer claramente la finalidad de la participación ayuda enormemente evitar las fluctuaciones elevaciones coyunturales movidas por el entusiasmo y momentos de dispersión y apatía, haciendo que la movilización se extinga por completo.

La participación se efectúa a partir del impulso y la fuerza que la motivación individual le imprime. Y para ello la concreción o logro de expectativas es fundamental, así como también de los haberes que pueden contarse en cuanto a enriquecimiento humano que se logra en el mismo proceso.

Lograr los fines de la participación (y más aun los que requieren mayor cantidad de tiempo para su concreción) supone una forma organizativa en la cual se canalicen con cierto orden y coherencia el conjunto de acciones pertinentes y necesarias para ello. Mejorar el hábitat o construir colectivamente el comunismo desde abajo no será posible sin formas organizativas en el medio popular. Sin que ello supongo superponer la organización en sí misma por encima del mismo proceso que debe conducir a concretarla.

Es pertinente asumir la importancia del liderazgoenlos procesos participativos. Ellopuede implicar el fracaso de éxito de la participación porque está estrechamente relacionado con el tipo de liderazgo que manifieste y se cultive. 
Si se tiene el ejercicio de un liderazgo que promueva de forma permanente la participación activadelaspersonas, motivándolas a desarrollarse, a dar de sí, así como a asumir un rol cada vez más protagónico dentro del proceso de participación, que promueve la delegación, la distribución de las tareas y la conformación de equipos en un marco de corresponsabilidad ello es garantía de éxito en la concreción de los objetivos planteados, no siendo así en los tipos de liderazgos más autocráticos que no motivan a la corresponsabilidad y afianza la dependencia y la sumisión.

Como ya hemos dicho participar no es una cuestión sencilla. En ella intervienen un conjunto de elementos que en no pocos casos se sobredeterminan dinámicamente unos a otros. En todo caso, la participación popular en las formas organizativas comunales es un proceso que está en marcha. Ningún proceso es puro desde sus inicios, ni se adecúa a un manual o teoría. Se efectúa en un contexto cultural, político económico, etc. concreto, que le imprime matices particulares. Lo importante es que se ha comenzado a andar.

\section{Referencias}

Arconada, S. (16 enero 2009). Carta abierta al Presidente Chávez. La conciencia. Aporrea. http://www.aporrea.org/actualidad/ a70514.html.

Constitución de la República Bolivariana de Venezuela (1999). Asamblea Nacional Constituyente, Caracas, Venezuela, 20 de diciembre de 1999.

Machado, Jesús. (2008) I Estudio de los consejos comunales. Caracas. Venezuela.

Moreno Alejandro. (2003). La participación como problema para una definición del concepto.
Revista Venezolana de Ciencia Política. № 24. Julio-Diciembre 2003. Pág. 162-178. Mérida.

Tanaka, M. (2001). Participación popular en las políticas sociales. Cómo y cuándo es democrática y eficiente, y por qué puede también ser lo contrario. http://old.cies. org.pe/files/documents/investigaciones/ pobreza/participacion-popular-en-laspoliticas-sociales.pdf

Ley De Los Consejos Locales De Planificación Pública FIDES - Gaceta Oficial de la República Bolivariana de Venezuela $\mathrm{N}^{\circ}$ 5.805 Extraordinario, de fecha 22 de Marzo de 2006.

Ley Orgánica del Poder Público Municipal. Gaceta Oficial $N^{\circ} 38.204$ de 8 de junio de 2005.

Ley de los Consejos Comunales (2006). Gaceta Oficial № 5.806 (Extraordinaria) de fecha 10 de abril de 2006.

Ley Orgánica de los Consejos comunales (2009). Gaceta Oficial № 39.335. de fecha 28 de diciembre de 2009.

\section{Prensa}

Willian Lara (7 de julio de 2008). La liberación de los consejos comunales. El Nacional, pág. A-4.

"Gobierno obliga a consejos comunales a trabajar por el Sí" (8 de enero de 2009). El Nacional. 